\title{
PENGARUH STRESS, MOTIVASI DAN KEPUASAAN KERJA TERHADAP KINERJA KARYAWAN
}

\author{
Albert dan Oey Hannes Widjaja \\ Program Studi Manajemen Fakultas Ekonomi Universitas Tarumanagara, Jakarta \\ Albert.115150325@stu.untar.ac.id
}

\begin{abstract}
The purpose of this study is to find out and analyze the influence of stress, motivation and work satisfaction on employee performance at PT One Six Eight Eight at Jakarta. This research was conducted by non-probability sampling method with a type of purposive sampling. The researcher distributed questionnaires to 35 employee at PT One Six Eight Eight at Jakarta. Data analysis using PLS SEM analysis. The results of the analysis conclude that stress, motivation and work satisfaction has a significant impact on employee performance.
\end{abstract}

Keyword: stress, satisfaction, motivation, employee performance

\begin{abstract}
Abstrak: Tujuan penelitian ini adalah untuk mengetahui dan menganalisa pengaruh pengaruh stress, motivasi dan kepuasan kerja terhadap kinerja karyawan pada PT Satu Enam Delapan Delapan di Jakarta. Penelitian ini dilakukan dengan metode non probability sampling dengan jenis purposive sampling. Peneliti menyebarkan kuesioner kepada 35 karyawan PT Satu Enam Delapan Delapan di Jakarta. Analisis data menggunakan analisis SEM PLS. Hasil analisis menyimpulkan bahwa stress, motivasi dan kepuasan kerja berpengaruh signifikan terhadap kinerja karyawan.
\end{abstract}

Kata Kunci: Stress, Kepuasan, Motivasi, Kinerja Karyawan

\section{LATAR BELAKANG}

Dalam dunia yang berubah dengan cepat saat ini, arena perusahaan dan bisnis menjadi sangat kompetitif. Untuk menghadapi persaingan ketat ini organisasi merangkul berbagai taktik dan strategi. Selain strategi dan taktik ini, salah satu faktor yang dapat memainkan peran integralnya untuk membantu organisasi dalam mencapai keunggulan kompetitif adalah karyawannya. Perencanaan sumber daya manusia dalam sebuah perusahaan akan dapat dilakukan dengan baik dan benar jika perusahaan mengetahui bagaimana kemampuan yang dimiliki sumber daya manusia di perusahaan. Sumber daya manusia terdiri dari daya pikir dan daya fisik pada setiap manusia. Tanpa peran aktif dari SDM

Kinerja adalah kuantitas atau kualitas sesuatu yang dihasilkan atau jasa yang diberikan oleh seseorang yang melakukan pekerjaan Kinerja karyawan merupakan suatu hal yang sangat penting dalam suatu perusahaan untuk mencapai target operasionalnya. Selain itu kinerja digambarkan sebagai keterampilan seseorang untuk mendapatkan tujuan pekerjaan mereka, menemukan kepercayaan atau harapan, serta mendapatkan standar dan keberhasilan dalam mencapai tujuan bagi karyawan dan organisasi

Ada beberapa penyebab yang bisa mempengaruhi perubahan pada kinerja karyawan, bahwa variabel motivasi, kepuasan kerja dan stres kerja secara statistik berpengaruh terhadap kinerja karyawan. Karyawan akan mengontrol stres kerjanya agar tidak menganggu 
konsentrasi dalam bekerja yang nantinya jika tidak dikontrol akan berakibat terhadap kinerja yang diperoleh kedepannya. Motivasi yang diberikan dan kepuasan kerja yang dirasakan oleh seluruh karyawan mengakibatkan karyawan akan terus mencoba untuk lebih baik lagi dalam bekerja untuk memenuhi target perusahaan.

\section{KAJIAN TEORI}

Kinerja Karyawan merupakan hasil dari proses kerja yang sudah dilewati dan menjadi gambaran proses kerja yang dilakukan. Menurut Yanuar (2017), kinerja merupakan fungsi dari kemampuan interaksi, motivasi, dan kesempatan untuk tampil. Kinerja yang tidak sesuai dengan target dapat menjadi sebuah indikator bahwa ada ketidak beresan atau penyimpangan dalam sebuah proses kerja yang dilakukan oleh seorang karyawan.

Stress Kerja adalah adanya ketidakseimbangan di antara tuntutan pekerjaan yang diberikan dengan kemampuan yang dimiliki sehingga menimbulkan tekanan. Stres kerja dapat memicu karyawan menjadi sulit untuk proses berpikir, meningkatkan ketegangan emosi, dan kecemasan yang kronis.

Kepuasan Kerja terkait dengan penilaian tentang karakteristik pekerjaan, lingkungan kerja, dan pengalaman emosional di tempat kerja. Karyawan yang puas mempunyai penilaian yang baik tentang pekerjaan mereka, berdasarkan pengamatan dan pengalaman mereka. Kepuasan Kerja dapat dilihat dari beberapa indicator :

1. Work it self ( Pekerjaan itu sendiri )

2. Pay ( Bayaran )

3. Promotion ( Promosi )

4. Supervision ( Pengawasan )

5. Coworkers ( Kolega)

6. Overall ( Keseluruhan )

Motivasi Kerja merupakan kondisi yang mendorong seseorang untuk dapat melakukan tugas-tugas atau pekerjaan sesuai dengan fungsinya masing-masing dalam suatu organisasi. Dengan kata lain motivasi kerja merupakan dorongan atau keinginan yang dimiliki oleh seseorang individu dengan perilaku tertentu dalam pekerjaan yang mereka lakukan dalam organisasi.

Berdasarkan teori diatas maka berikut ini adalah hubungan antar variabel dalam penelitian ini seperti digambarkan dibawah ini : 


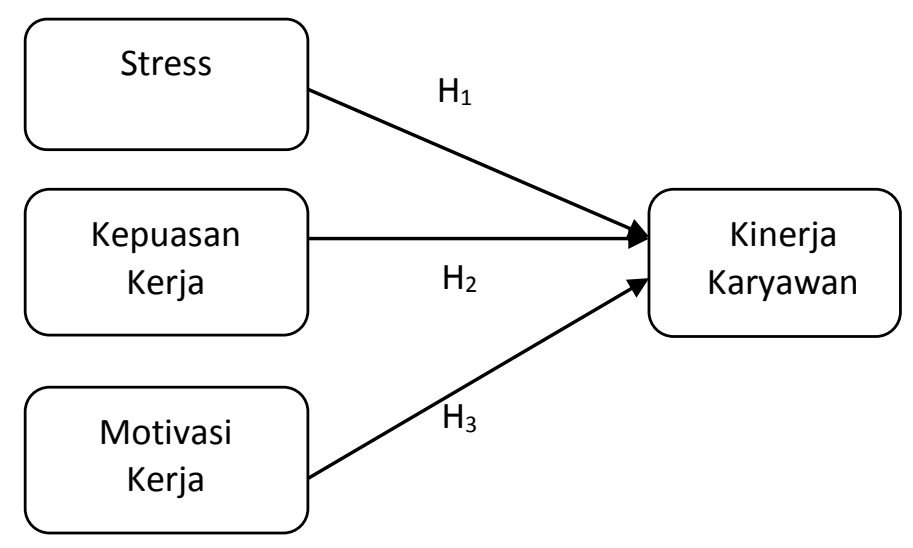

Gambar 1. Kerangka Pemikiran

Hipotesis:

H1 : Stress berpengaruh signifikan terhadap kinerja karyawan

H2 : Kepuasan Kerja berpengaruh signifikan terhadap kinerja karyawan

H3 : Motivasi Kerja berpengaruh signifikan terhadap kinerja karyawan

\section{METODOLOGI}

Jenis penelitian ini tergolong jenis penelitian kausal yaitu penelitian yang menunjukkan hubungan sebab akibat. Dalam penelitian kausal ada variabel yang mempengaruhi dan variabel yang dipengaruhi (Sugiyono, 2018). Desain penelitian yang digunakan termasuk dalam penelitian survei.

Data yang digunakan pada penelitian ini merupakan data primer yaitu data yang diperoleh secara langsung dari sumber pertama. Maka pengumpulan data penelitian dilakukan dengan menyebarkan kuesioner secara langsung kepada responden yang akan diteliti yaitu kepada karyawan PT Satu Enam Delapan Delapan di Jakarta.

Teknik pengambilan sampel dalam penelitian ini dengan teknik non probability sampling, yaituteknik pengambilan sampel yang tidak memberikan peluang yang sama bagi setiap unsur (anggota) populasi untuk dipilih menjadi anggota sampel.

Pada penelitian ini, data para responden yang telah terkumpul, akan digunakan untuk menganalisis data peneliti dengan menggunakan analisis structural equation model (SEM), lalu data tersebut akan diolah menggunakan software smartPLS. Analisis inner model bertujuan untuk mengetahui hubungan antar variabel yang terdapat di dalam penelitian (Hair et al., 2014).

\section{HASIL ANALISIS DATA}

Berdasarkan hasil Average Variance Extracted (AVE) terlihat bahwa seluruh variabel yang diteliti menunjukkan nilai AVE lebih besar dari kriteria 0,5. Sehingga dapat disimpulkan bahwa indikator-indikator pengukuran konstruk variabel sudah memiliki korelasi tinggi. 
Tabel 1. Hasil Uji Average Variance Extracted (AVE)

\begin{tabular}{|l|l|}
\hline Variabel & Average Variance Extracted (AVE) \\
\hline Kepuasan Kerja (X2) & 0.600 \\
\hline Kinerja Karyawan (Y) & 0.601 \\
\hline Motivasi Kerja (X3) & 0.672 \\
\hline Stress (X1) & 0.675 \\
\hline
\end{tabular}

Tabel 2. Hasil Uji Reabilitas

\begin{tabular}{|l|l|}
\hline Variabel & $\begin{array}{l}\text { Cronbach's } \\
\text { Alpha }\end{array}$ \\
\hline Kepuasan Kerja (X2) & 0.867 \\
\hline Kinerja Karyawan (Y) & 0.867 \\
\hline Motivasi Kerja (X3) & 0.902 \\
\hline Stress (X1) & 0.939 \\
\hline
\end{tabular}

Menurut Sarwono \& Budiono (2012), uji reliabilitas digunakan untuk menghitung reliabilitas model yang menunjukkan adanya indikator-indikator yang mempunyai derajat kesesuaian yang baik dalam satu model satu dimensi. Nilai yang semakin mendekati angka 1 dianggap semakin reliabel. Dan Menurut Hasil uji reliabilitas pada tabel 2 menunjukkan bahwa seluruh nilai koefisien cronbach's alpha pada masing-masing variabel memiliki nilai lebih besar dari 0,6. Maka dapat disimpulkan bahwa instrumen yang digunakan untuk mengukur variabel-variabel pada penelitian ini sudah reliabel atau layak digunakan untuk langkah pengolahan data selanjutnya.

Tabel 3. Hasil Uji R Square

\begin{tabular}{|l|l|}
\hline Variabel & $\boldsymbol{R}$ Square \\
\hline Kinerja Karyawan $(\mathrm{Y})$ & 0.803 \\
\hline
\end{tabular}

Dari hasil pengujian koefisien determinasi pada Tabel 3 di atas, dapat diketahui bahwa nilai $R$ square yang dihasilkan adalah sebesar 0,803. Hasil ini dapat diartikan bahwa sebesar 80,3\% dari Kinerja Karyawan dapat dijelaskan oleh variabel-variabel yang terdapat dalam penelitian ini yaitu stress, kepuasan kerja dan motivasi kerja sedangkan sisanya yaitu sebesar 19,7\% dijelaskan oleh variabel-variabel yang tidak dimasukkan ke dalam penelitian ini.

Tabel 4. Hasil Path Coefficient

\begin{tabular}{|l|l|l|l|}
\hline Hubungan Variabel & $\begin{array}{l}\text { Path } \\
\text { coefficients }\end{array}$ & T-Statistics & P-Values \\
\hline Stress (X1) -> Kinerja Karyawan (Y) & -0.354 & 2.306 & 0.022 \\
\hline
\end{tabular}




\begin{tabular}{|l|l|l|l|}
\hline $\begin{array}{l}\text { Kepuasan Kerja (X2) -> Kinerja } \\
\text { Karyawan (Y) }\end{array}$ & 0.388 & 3.340 & 0.001 \\
\hline $\begin{array}{l}\text { Motivasi Kerja (X3) -> Kinerja } \\
\text { Karyawan (Y) }\end{array}$ & 0.396 & 2.432 & 0.015 \\
\hline
\end{tabular}

Dari hasil path coefficient yang disajikan pada Tabel 4 di atas, maka dapat diperoleh persamaan dalam penelitian ini yaitu KK $=-0.354 \mathrm{ST}+0.388 \mathrm{KEP}+0.396 \mathrm{MO}$. Nilai path coefficients tersebut menunjukkan bahwa nilai prediksi variabel stress terhadap kinerja karyawan memiliki koefisien jalur yang menunjukkan arah negatif atau berbanding terbalik yaitu sebesar -0,354. Artinya adalah jika stress mengalami peningkatan maka kinerja karyawan di perusahaan akan semakin menurun. Kemudian nilai path coefficients kepuasan kerja terhadap kinerja karyawan menunjukkan arah yang positif atau searah yaitu sebsar 0,388. Artinya adalah jika kepuasan kerja mengalami peningkatan maka kinerja karyawan di perusahaan juga akan mengalami peningkatan. Nilai path coefficients motivasi kerja terhadap kinerja karyawan menunjukkan arah yang positif atau searah yaitu sebsar 0,396. Artinya adalah jika motivasi kerja mengalami peningkatan maka kinerja karyawan di perusahaan juga akan mengalami peningkatan.

Tabel 5. Hasil Uji Signifikansi

\begin{tabular}{|l|l|l|}
\hline Hubungan Variabel & T-Statistics & P-Values \\
\hline Stress (X1) -> Kinerja Karyawan (Y) & 2.306 & 0.022 \\
\hline Kepuasan Kerja (X2) -> Kinerja Karyawan (Y) & 3.340 & 0.001 \\
\hline Motivasi Kerja (X3) -> Kinerja Karyawan (Y) & 2.432 & 0.015 \\
\hline
\end{tabular}

Hipotesis pertama dalam penelitian ini adalah:

$\mathrm{H}_{1}$ : Stress berpengaruh signifikan terhadap kinerja karyawan PT 1668.

Berdasarkan hasil pada Tabel 4.12, dapat diketahui bahwa variabel stress berpengaruh signifikan terhadap kinerja karyawan PT 1668. Hal ini dibuktikan dengan nilai $t$ statistics sebesar 2.306 yang lebih besar dari cut off value sebesar 1,96. Kemudian $p$ values yang dihasilkan adalah sebesar 0,022 lebih kecil dari cut off value yang ditetapkan yaitu sebesar 0,05. Sehingga dapat disimpulkan bahwa $\mathrm{H}_{1}$ diterima.

Hipotesis kedua dalam penelitian ini adalah:

$\mathrm{H}_{2}$ : Kepuasan kerja berpengaruh signifikan terhadap kinerja karyawan PT 1668.

Berdasarkan hasil pada Tabel 4.12, dapat diketahui bahwa variabel Kepuasan kerja berpengaruh signifikan terhadap kinerja karyawan PT 1668. Hal ini dibuktikan dengan nilai $t$ statistics sebesar 3.340 yang lebih besar dari cut off value sebesar 1,96. Kemudian $p$ values yang dihasilkan adalah sebesar 0,001 lebih kecil dari cut off value yang ditetapkan yaitu sebesar 0,05. Sehingga dapat disimpulkan bahwa $\mathrm{H}_{2}$ diterima.

Hipotesis ketiga dalam penelitian ini adalah:

$\mathrm{H}_{3}$ : Motivasi kerja berpengaruh signifikan terhadap kinerja karyawan PT 1668.

Berdasarkan hasil pada Tabel 4.12, dapat diketahui bahwa variabel Motivasi kerja berpengaruh signifikan terhadap kinerja karyawan PT 1668. Hal ini dibuktikan dengan nilai $t$ statistics sebesar 2.432 yang lebih besar dari cut off value sebesar 1,96. Kemudian $p$ values yang 
dihasilkan adalah sebesar 0,015 lebih kecil dari cut off value yang ditetapkan yaitu sebesar 0,05. Sehingga dapat disimpulkan bahwa $\mathrm{H}_{3}$ diterima.

\section{DISKUSI}

Dari uraian hasil deskripsi tanggapan responden secara keseluruhan, diketahui kebanyakan responden menjawab tidak setuju pada variabel stress, dan jawaban setuju pada kepuasan kerja, motivasi kerja, dan kinerja karyawan. Hal ini menandakan bahwa stres yang rendah, kepuasan kerja dan motivasi kerja yang tinggi di PT 1668 akan berdampak pada meningkatnya kinerja karyawan.

Berdasarkan hasil outer model analysis, semua indikator pada variabel stress, kepuasan kerja, motivasi kerja dan kinerja karyawan sudah dinyatakan valid karena telah memenuhi kriteria convergent validity yaitu memiliki nilai loading factor $>0,5$, dan ketiga variabel juga menunjukkan nilai AVE yang lebih besar dari 0,5. Pada pengujian discriminant validity, diperoleh hasil bahwa nilai cross loading masing-masing variabel lebih besar nilai cross loadings variabel konstruk lainnya. Selanjutnya pada pengujian reliabilitas menggunakan cronbach's alpha, seluruh indikator pada variabel yang diteliti juga dinyatakan reliable dengan nilai cronbach's alpha di atas 0,6 yang berarti alat ukur kuesioner yang digunakan dalam penelitian ini dapat diandalkan untuk mengukur variabel stress, kepuasan kerja, motivasi kerja dan kinerja karyawan pada PT 1668.

Pada pengujian inner model analysis, hasil pengujian $\mathrm{R}$ Square $\left(\mathrm{R}^{2}\right)$ dalam penelitian ini menunjukan nilai sebesar 0,803. Hasil ini dapat diartikan bahwa sebesar 80,3\% dari Kinerja Karyawan dapat dijelaskan oleh variabel-variabel yang terdapat dalam penelitian ini yaitu stress, kepuasan kerja, motivasi kerja sedangkan sisanya yaitu sebesar 19,7\% dijelaskan oleh variabel-variabel yang tidak dimasukkan ke dalam penelitian ini. Selanjutnya hasil dari pengujian goodness of fit pada penelitian ini adalah sebesar 0,715. Dari hasil perhitungan nilai goodness of fit tersebut, maka dapat disimpulkan bahwa model yang digunakan pada penelitian ini memiliki goodness of fit atau kecocokan model penelitian yang termasuk kategori besar atau tinggi karena nilai yang dihasilkan lebih dari 0,38.

Pada pengujian koefisien jalur (path coefficient), diperoleh persamaan yaitu: $\mathrm{KK}=-$ $0.354 \mathrm{ST}+0.388 \mathrm{KEP}+0.396 \mathrm{MO}$. Nilai path coefficients tersebut menunjukkan bahwa nilai prediksi variabel stress terhadap kinerja karyawan memiliki koefisien jalur yang menunjukkan arah negatif atau berbanding terbalik yaitu sebesar $-0,354$. Artinya adalah jika stress mengalami peningkatan maka kinerja karyawan di perusahaan akan semakin menurun. Kemudian nilai path coefficients kepuasan kerja terhadap kinerja karyawan menunjukkan arah yang positif atau searah yaitu sebsar 0,388 . Artinya adalah jika kepuasan kerja mengalami peningkatan maka kinerja karyawan di perusahaan juga akan mengalami peningkatan. Nilai path coefficients motivasi kerja terhadap kinerja karyawan menunjukkan arah yang positif atau searah yaitu sebsar 0,396. Artinya adalah jika motivasi kerja mengalami peningkatan maka kinerja karyawan di perusahaan juga akan mengalami peningkatan.

Hasil pengujian hipotesis pertama menunjukkan bahwa $\mathrm{H} 1$ diterima. Dalam hal ini variabel stress berpengaruh signifikan terhadap kinerja karyawan PT 1668. Hal ini dibuktikan dengan nilai $t$ statistics sebesar 3.159 yang lebih besar dari cut off value sebesar 1,96. Kemudian 
$p$ values yang dihasilkan adalah sebesar 0,002 lebih kecil dari cut off value yang ditetapkan yaitu sebesar 0,05 .

Hasil pengujian hipotesis kedua menunjukkan bahwa H2 diterima. Dalam hal ini variabel Kepuasan kerja berpengaruh signifikan terhadap kinerja karyawan PT 1668. Hal ini dibuktikan dengan nilai $t$ statistics sebesar 2.602 yang lebih besar dari cut off value sebesar 1,96. Kemudian $p$ values yang dihasilkan adalah sebesar 0,010 lebih kecil dari cut off value yang ditetapkan yaitu sebesar 0,05 .

Hasil pengujian hipotesis ketiga menunjukkan bahwa H3 diterima. Dalam hal ini variabel Motivasi kerja berpengaruh signifikan terhadap kinerja karyawan PT 1668. Hal ini dibuktikan dengan nilai $t$ statistics sebesar 2.602 yang lebih besar dari cut off value sebesar 1,96. Kemudian $p$ values yang dihasilkan adalah sebesar 0,010 lebih kecil dari cut off value yang ditetapkan yaitu sebesar 0,05 .

Dari ketiga variabel yang diuji, faktor kepuasan kerja memiliki koefisien pengaruh yang lebih besar terhadap kinerja karyawan PT 1668 jika dibandingkan dengan variabel stress dan motivasi kerja. Hal ini dikarenakan variabel kepuasan kerja memiliki nilai signifikansi $(0,001)$ yang lebih kecil dibandingkan variabel variabel stress dan motivasi kerja.

\section{PENUTUP}

Penelitian ini bertujuan untuk mengetahui apakah stress, kepuasan dan motivasi kerja berpengaruh terhadap kinerja karyawan PT 1668 di Jakarta. Pengolahan data pada penelitian ini menggunakan program Smart PLS 3.00. Berdasarkan hasil dan pembahasan yang telah dijelaskan pada Bab sebelumnya, maka penulis menarik kesimpulan, sebagai berikut:

1. Stress berpengaruh signifikan terhadap kinerja karyawan PT 1668. Hal ini dibuktikan dengan nilai $t$ statistics sebesar 3.159 yang lebih besar dari cut off value sebesar 1,96. Kemudian $p$ values yang dihasilkan adalah sebesar 0,002 lebih kecil dari cut off value yang ditetapkan yaitu sebesar 0,05. Koefisien jalur bernilai negatif atau berbanding terbalik artinya apabila stres meningkat maka kinerja karyawan PT 1668 akan semakin menurun.

2. Kepuasan kerja berpengaruh signifikan terhadap kinerja karyawan PT 1668. Hal ini dibuktikan dengan nilai $t$ statistics sebesar 2.602 yang lebih besar dari cut off value sebesar 1,96. Kemudian $p$ values yang dihasilkan adalah sebesar 0,010 lebih kecil dari cut off value yang ditetapkan yaitu sebesar 0,05 . Koefisien jalur bernilai positif artinya apabila Kepuasan kerja meningkat maka kinerja karyawan PT 1668 akan semakin meningkat

Motivasi kerja berpengaruh signifikan terhadap kinerja karyawan PT 1668. Hal ini dibuktikan dengan nilai $t$ statistics sebesar 2.602 yang lebih besar dari cut off value sebesar 1,96. Kemudian $p$ values yang dihasilkan adalah sebesar 0,010 lebih kecil dari cut off value yang ditetapkan yaitu sebesar 0,05. Koefisien jalur bernilai positif artinya apabila Motivasi kerja meningkat maka kinerja karyawan PT 1668 akan semakin meningkat. 


\section{DAFTAR PUSTAKA}

Abdillah, W., \& Hartono, J. (2015). Partial Least Square (PLS). Yogyakarta: Andi

Alpahrasy, R. dan Nasution. (2017). Pengaruh Motivasi, Kepuasan Kerja, dan Stres Kerja Terhadap Kinerja Karyawan Pt Toyota Agung Automall Bengkulu, Management Insight, Vol 12, No 2: 1-12.

Arshadi, N., \& Damiri, H. (2013). The Relationship of Job Stress with Turnover Intention and Job Performance: Moderatingrole of OBSE. Procedia-Social and Behavioral Sciences, Vol 84, hal 706-710.

Fahmi, I. (2014). Perilaku Organisasi: Teori, Aplikasi, dan Kasus. Cetakan Kedua. Bandung: Alfabeta.

Ghozali, I. (2014). Structural Equation Modeling, Metode Alternatif dengan Partial Least Square (PLS) (4th ed.). Semarang: Badan Penerbit Universitas Diponegoro

Hair, J. F., Hult, G. T. M., Ringle, C. M., \& Sarstedt, M. 2017. A Primer on Partial Least Squares Structural Equation Modeling (PLS-SEM) (2nd ed.). CA: Sage Publications Inc

Hasibuan, Malayu S.P. (2017). Manajemen Sumber Daya Manusia. Edisi Revisi. Cetakan Ke21. Jakarta: Bumi Aksara

Hassan, M., Azinat, U., Sarwar, S., Adil, I.H., \& Gillani, S.H.M. (2020). Impact of Job Satisfaction, Job Stress and Motivation on Job Performance: a Case from Private Universities of Karachi. Arabian Journal of Business and Management Review, Vol 9, No 2: 31-41.

Hermawan, H., Brahmanto, E., \& Hamzah, F. (2018). Pengantar Manajemen Hospitality. Jawa Tengah: PT Nasya Expanding Management.

Hon, A. H., Chan, W. W., \& Lu, L. (2013). Overcoming work-related stress and Promoting Employee Creativity in HotelIndustry: The Role of Task Feedback From Supervisor. International Journal of Hospitality Management, Vol 33, hlm 416-424

Kristanti, D dan Pangastuti, R.L. (2019). Effect of Work Stress, Work Motivation, and Work Environment to Employee Performance Production Part (Case Study at UD Pratama Karya Kota Kediri). Business and Finance Journal, Volume 4, No. 2, hal 105-114.

Latiho, R.S. (2016). Analisis Pengaruh Kepuasan, Motivasi, dan Stres Kerja Terhadap Kinerja Tenaga PARAMEDIS Keperawatan di RSUD Kabupaten Morowali, Jurnal Katalogis, Volume 4 Nomor 8, hlm 62-72.

Lawler III, Edward E. dan Porter, Lyman W. (1967). 'The Effect of Performance on Job Satisfaction'. Industrial Relations, a Journal of Economy and Society. Vol. 7, no.1, pp. 20-28.

Luthans, F. (2015). Organizational Behavior. New York: McGraw-Hill

Malhotra, N. K. (2010). Marketing Research. New Jersey: Pearson Education

Mangkunegara, A.A. Anwar Prabu. (2014). Manajemen Sumber Daya Manusia. Bandung: Remaja Rosdakarya

Priyono. (2007). Pengantar Manajemen. Cet. 1. Surabaya: Zifatama Publisher

Rivai, Vethzal \& Basri. (2015). Peformance Appraisal: Sistem yang Tepat untuk Menilai Kinerja Karyawan dan Meningkatkan Daya Saing Perusahan. Jakarta: PT. RajaGrafindo Persada

Robbins, S. P., \&Coulter, M. (2014). Manajemen. Jakarta: Erlangga.

Robbins, S. P., \& Judge, T. A. (2016). Essentials of Organizational Behavior (13th ed.). USA: Pearson Education, Inc.

Sarwono, Jonathan dan Budiono Herlina. (2012). Statistik Terapan Aplikasi untuk Riset 
Skripsi, Tesis, dan Disertasi menggunakan SPSS, AMOS dan Excel.Jakarta : PT. Elex Media Komputindo-Kompas Gramedia.

Sekaran, U., \& Bougie, R. (2013). Research Methods for Business: A Skill-Building Approach (6th ed.). New York: John Wiley and Sons, Inc

Sugiyono. (2018). Metode Penelitian Manajemen. Bandung: Alfabeta

Sujarweni, V. W. (2014). SPSS Untuk Penelitian. Yogyakarta: Pustaka Baru Press

Sunyoto, D. (2016). Teori, Kuesioner, dan Proses Analisis Data Perilaku Organisasional. Yogyakarta: CAPS

Wibowo. (2016). Manajemen Kinerja (5th ed.). Jakarta: Raja Grafindo Persada

Yanuar, Y. (2017). Compensation, motivation and performance of employees: Evidence from Indonesia. Journal of Economic \& Management Perspectives, 11(4), 486-492.

Yuliawan, E. (2012). Pengaruh Stres Kerja dan Konflik Terhadap Kinerja Karyawan Pada PT. Pindan Bandung. Jurnal Wira Ekonomi Mikroskill,Vol. 2. 